\title{
Interpretation of the Connotation of Weaving and Embroidery of Traditional Clothing of Blue Clothes Zhuang
}

Qiyi Wu

Guangxi College for Preschool Education, Nanning 530022, Guangxi, China.

Project: 2020 Guangxi Young and Middle-aged Teachers' Basic Ability Improvement Project: Narrative Research on Weaving and Embroidery Patterns of Traditional Blue Clothes Zhuang (No.: 2020KY28014)

Abstract: Zhuang nationality clothing patterns are colorful and rich in connotation, including flowers, plants, trees, insects, fish, birds and animals. Among the numerous patterns and patterns, some widely used totems have different applications in different parts of traditional clothing. From the perspective of the traditional clothes of blue clothes Zhuang nationality, the Southern Zhuang nationality and the northern one live in different areas, so different national aesthetic constructs different embroidery art characteristics. The plain Zhuang embroidery is mostly humble embroidery, and the mountain Zhuang in the northern Guangxi mountain area is mostly skillful embroidery, which are well-made, showing the classic national characteristics. In this paper, through the analysis of the traditional clothing embroidery pattern of blue clothing Zhuang, the cultural connotation and value of related clothing decoration are studied.

Keywords: blue clothes Zhuang; traditional clothing; weaving and embroidery; decoration; connotation

Patterns play an important role in ornamentation and decoration in clothing. Just like the makeup artist, patterns add luster to the plain blue clothing and make the characteristics of the clothing more prominent, so as to show the charm and advantages of the clothing. Even if it is a trivial little decoration, the decorative effect that can be played in different parts of clothing with unexpected result sometimes, and it is also a perfect presentation of the aesthetic emotion of the designer ${ }^{[1]}$. In the selection of traditional clothing embroidery pattern of blue clothes Zhuang, the related patterns have their specific theme, significance and value, showing different sentiment and style. In the traditional costumes of the blue clothes Zhuang, the related pictures and decorations are not isolated from each other. They all have their specific meanings and connections, and also carry the traditional cultural information of Zhuang nationality. In the observation of blue clothes Zhuang traditional clothing, we can learn many historical allusions and excellent folk culture and art of Zhuang nationality development. We can also taste the exquisite craftsmanship with delicate mind of garment makers and feel their love for life and nation. Clothing is not only a symbol of national culture, but also a "spring" to moisten people's hearts ${ }^{[2]}$.

\section{Commonly used patterns in weaving and embroidery of traditional clothing of blue clothes Zhuang}

Pictorial decoration is the cultural symbol of the blue clothes Zhuang, which has experienced a long process from its emergence to development. However, the related decoration culture has always maintained close contact with the region and nationality, fully reflecting the production, religion, morality, customs, cultural values and aesthetic taste and so on of the region. In the weaving and embroidery of Zhuang clothing, there are various patterns of commonly used patterns, including flowers, birds, fish and insects in nature, as well as totems and imaginary objects in national culture ${ }^{[3]}$. However, there is no accurate statistics on the number of patterns contained in the traditional clothing embroidery

Copyright $\odot 2020$ Qiyi Wu

doi: $10.18282 /$ le.v9i6.1304

This is an open-access article distributed under the terms of the Creative Commons Attribution Non-Commercial License

(http://creativecommons.org/licenses/by-nc/4.0/), which permits unrestricted non-commercial use, distribution, and reproduction in any medium, provided the original work is properly cited. 
of blue clothes Zhuang. From the perspective of the theme of relevant patterns, there are geometric patterns, animal patterns, plant patterns, figure patterns and so on. Among them, animals, plants and geometric patterns are most commonly used in traditional clothing embroidery patterns. This phenomenon is the ancestors of the Zhuang nationality copying the specific images around them. The pattern from concrete to abstract is going through a long process of development, extending from the things around to other aspects, or directly using the national totem worship symbols as the patterns used in weaving and embroidery. In the application of various patterns, many conventional patterns have their specific cultural connotations, presenting the social content and aesthetic taste of Zhuang nationality ${ }^{[4]}$.

\section{Traditional weaving and embroidery techniques and color application of blue clothes Zhuang}

\subsection{Weaving and embroidery techniques of traditional clothing in blue clothes Zhuang}

The traditional clothing embroidery technology of blue clothes Zhuang is mainly manual embroidery, which is all the unique skills of women of Zhuang nationality. With relatively complex process, manual embroidery is difficult and time-consuming. However, the pattern of manual embroidery is exquisite and not easy to damage. Zhuang's traditional embroidery is closely related to Yao embroidery and Miao embroidery. It is mainly flat embroidery, which is also called fine embroidery. One of the Chinese embroidery species, is an embroidery which is carried out on the flat substrate by using such needling techniques as flat needling, swing stitch, trowel stitch and needle application. The blue clothe Zhuang in north of Gui is the most common embroidery method. In the process of inheritance and development of generations of artists, flat embroidery techniques have produced a variety of different embroidery and needling techniques, which embroidery surface is meticulous, delicate and full of texture. Cloth stick embroidery is a kind of embroidery which is shaped by cutting out the shape of colored cloth and inlaying with lace. It is also popular in the north of Gui, while the blue clothes Zhuang embroidery in central and southern Gui is mainly composed of back stitch embroidery in the traditional plain embroidery. The design is realistic and concise, reflecting the relatively humble artistic taste.

In the sixties of last century, in order to improve the efficiency of Zhuang brocade weaving, weaving machine was introduced into Zhuang brocade area. This kind of mechanical equipment was originally used to weave Shu brocade, which can realize the orderly arrangement of flower plates in embroidery. The jacquard device of the weaving machine can realize the weaving of square continuous small flower pattern with small number of knitting needles, which can meet the needs of weaving and embroidery technology for wider fabrics. Compared with the traditional Zhuang embroidery technology, the efficiency has increased nearly three times ${ }^{[5]}$.

\subsection{Application of embroidery color in traditional clothing of blue clothes Zhuang}

Zhuang people's love of red is related to national customs. Their choice of red is usually when they celebrate "red affairs", such as new life, new marriage, new year, new creation, etc. In the past, eggs were often painted red to pray for more children and more happiness and the birth of a baby is undoubtedly regarded as a red affair. New marriage is a typical representative of red affair, which is related to the traditional sex culture "red flower girl". During the Chinese new year, people use red paper to pray for good luck in the coming year, and express their good wishes and happy mood. If red is the color of Zhuang people's "life", and then black is the color of "existence", that is, a transitional color from life to death. This is the color of living significance of Zhuang people. Most of the Zhi family of the Zhuang nationality wore black clothes from ancient times to the early days of liberation, including men, women, old and young. In the environment where many ethnic groups live together, it is of special significance for Zhuang people to use pure black as their clothing color for a long time and on a large scale.

Pure white is regarded as the color of "death" among Zhuang people. When a person dies, it is called "white affairs". The elegy couplet is written in white paper with the curtain is drawn with white cloth and the white paper string is inserted on the grave, as well as the animals made of white paper are placed at the edge of the grave. The people who participate in the Funeral (especially the filial piety men and daughters) wear white clothes or black clothes, with white cloth covering their heads and waist. Because the traditional custom of white is used for funerals, the Zhuang people are very taboo of white in their daily life, and even pay attention to giving white poultry to others.

In addition to black, red and white, Zhuang people also choose and apply a variety of colors at the same time. The choice of mixed colors by Zhuang people can be seen in the traditional food glutinous rice making and the production 
technology of the ball made of strips of silk. The skillful Zhuang girls first made orange petals with red shells or multilayer cloth, and embroidered various delicate and lively patterns and patterns full of folk implication with colored silk or colored cloth on each petal ${ }^{[6]}$.

\section{Embroidery patterns implication in traditional clothing of blue clothes Zhuang}

\subsection{Flower Goddess}

Since ancient times, people's worship of the earth has never diminished. In their beliefs, blue clothes Zhuang people regard Flower Goddess Mi Luojia as the God of creation. According to the legend of Zhuang people, Flower Goddess is a flower born on the earth. She is in charge of women's childbirth and protects children's health. Zhuang people believe that the flowers in Flower Goddess courtyard are children, and whether flowers can thrive depends on the care of her. Zhuang people's worship of flowers begins with the idea that land breeds life, which is the instinct of Zhuang ancestors to establish themselves. They also agree with the totem culture and the difficulty and harmonious order of Jupiter's social structure. With realization for self-consciousness development under this identity, Zhuang people's identification of the origin of floral ancestry is also the self-identity of Zhuang nationality.

\subsection{Frog worship}

In the legend of Zhuang nationality, frog is regarded as the son of Thunder God, and is placed on the good wish of harmonious coexistence between man and nature. As far as the habitation of blue clothes Zhuang people is concerned, the area has a lot of precipitation with good geographical conditions and the rice is the most important crop. In the primitive times, the ancestors of Zhuang nationality developed rice planting technology in practice, which brought great changes to the life style of Zhuang people. In the past, the Zhuang people who had no permanent residence began to settle down and gradually developed their national language, culture and art in the production process, which constituted a unique cultural connotation. Rice is an important object for Zhuang people to hope for a bumper harvest, so frog totem is derived, hoping to use this sacred relic to protect the wind and rain so as to achieve a bumper harvest.

\section{Conclusion}

From the perspective of the decoration connotation of blue clothes Zhuang in the traditional clothing weaving and embroidery, the formation and development of relevant patterns have their specific history, especially the profound national cultural connotation. They are the wisdom crystallization of the Zhuang people and their national beliefs. The traditional clothing embroidery patterns represent the national culture. It is formed and developed gradually in the longterm regional life of the nationality, which is also of great significance to the cultural inheritance and development in ethnic areas.

\section{References}

1. Zhan Lin.Research on the Aesthetic Trend of Zhuang Brocade Embroidery in Contemporary Zhuang Costume. Humanistic World,2016(18):118-120.

2. Xin wu.Pursuing the Traditional Culture of Suzhou and Indulging in the Ancient Costumes of Jiangnan by Ancient Embroidery Collector Li Pinde. Collection,2015(21):136-143.

3. Wang Hualin.On the Aesthetic Trend of Zhuang Brocade Technology in the Application of Contemporary Zhuang Costume.Journal of the Central University for Nationalities (Philosophy and Social Sciences),2015,42(03):146-149.

4. li Hong.Activating Tradition with Fashion_- Taking the Protection of Chinese Weaving and Embroidery Printing and Dyeing Process in "Intangible Cultural Heritage" as An Example.Museum Research,2011(03):13-18.

5. Chen Lihao.National Symbol, National Spirit_— Brief Analysis on the Aesthetic Value of Li Nationality's Traditional Costume.Journal of Qiongzhou University,2011,18(01):13-16.

6. Luo Qilian.The Choice and Understanding for Color of Zhuang Nationality. Movie Review,2008,(18):86,95. 